\title{
Towards Cellular Activation of an Artificial Metalloenzyme: Development of an Artificial Zymogen
}

\author{
Vincent Lebrun $\S^{\star *}$ \\ §SCS-DSM Award for best poster presentation in Catalysis Science \& Engineering
}

\begin{abstract}
Regulation of enzymatic activity is essential for living organisms. Nowadays, with the emergence of synthetic biology, there is a rising interest in placing the activity of synthetic catalysts under the control of a cell. This short review aims at summarizing the regulation strategies developed to date, and at presenting the development of an artificial zymogen, which is upregulated by a natural protease. In our view, this constitutes a first step towards the cellular control of the activity of an artificial metalloenzyme.
\end{abstract}

Keywords: Artificial metalloenzyme · Catalysis · Cross regulation · Transfer hydrogenation · Zymogen

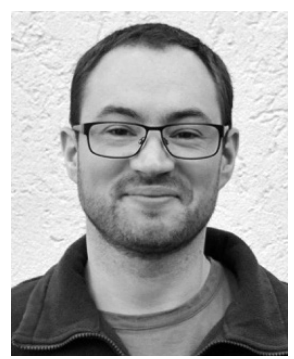

Vincent Lebrun received his $P h D$ in chemistry in 2014 from the University Grenoble Alpes under the guidance of Dr. O. Sénèque and Dr. J.-M. Latour, on metallopeptides modeling zinc finger sites. He currently is a postdoc fellow in the group of Prof. T. R. Ward at the University of Basel, focusing on the use of peptides to control the activity of artificial metalloenzymes based on streptavidin.

Synthetic biology is the engineering of biological or artificial living systems to endow them with new-to-nature functions. ${ }^{[1]}$ The 'top-down' approach of synthetic biology aims at integrating human-made components into the highly complex chemical networks constitutive of a natural living cell. For its own survival (e.g. adaption to a changing environment, phases of the life cycle), a cell needs to control the activity of the components of the cellular machinery,

\footnotetext{
${ }^{*}$ Correspondence: Dr. V. Lebrun

Department of Chemistry

University of Basel

$\mathrm{CH}-4056$ Basel

E-mail: vincent.lebrun@unibas.ch
}

namely, the enzymes. Biology has evolved different strategies to achieve such regulation: i) controlling the concentration of an enzyme (i.e. transcriptional or translational regulation), ii) inhibition by product or substrate, iii) allosteric regulation (i.e. binding of a small molecule at a regulatory site), iv) reversible covalent modification (e.g. phosphorylation, glutathionylation), and v) specific proteolysis..[2] Although the latter is the most common mechanism for protein inactivation, it is also widely used for activation. ${ }^{[3]}$ Some enzymes are indeed expressed as inactive pro-enzymes, called zymogens, which require limited proteolysis by a cognate protease to gain their catalytic activity. This allows a biological organism to temporally and spatially control the activity of such enzymes, avoiding their potential drawbacks (e.g. cytotoxicity).

If enzymes and ribozymes are responsible for the majority of biological catalysis, humans started to develop catalytic molecules to facilitate chemical reactions that are of interest, not of one organism, but of a society (e.g. fertilizers, pesticides, polymers). Their development is based on the growing knowledge of chemistry. Today, this comprehension of the principles of chemistry enables the human engineering of regulation systems for chemical catalysts, allowing chemists to better control their reactions, and it holds high potential for industry. Most of the regulation strategies that have been developed to date are based on inducing either i) a change in the electronic properties of the catalyst or ii) a conformational change (masking the active site or breaking the preorganization of cooperative sites). ${ }^{[4]}$ A handful of signals have been used:
- $\mathrm{pH}$ : Protonation of a ligand of the metal catalyst modifies its i) electron donation properties, thereby influencing catalysis. Other systems were developed in which a catalytic site of a $\mathrm{pH}$-switchable rotaxane can be ii) masked by the rotaxane's ring, depending on the $\mathrm{pH}$.

- Redox potential: An obvious way to control the catalytic activity is by i) changing the oxidation state of the catalytic metal. Alternatively, redox-active groups were added to the ligands of the catalytic metal. The oxidation state can influence ii) the electron donating properties of the ligand, iii) the substrate preference, iv) the enantioselectivity of the reaction or v) the solubility.

- Light: Photo-switches have been developed, based on photo-induced structural rearrangement, that control a catalyst's activity via i) masking/unmasking the catalytic site or ii) setting/breaking the essential pre-organization of cooperative sites. For this purpose, $E / Z$ photo-isomerizable groups (e.g. azobezene, stilbene), or even a unidirectional molecular motor have been used. Photo-induced ring-opening/ring-closing groups (e.g. dithienylethene, spiropyran) were used to iii) switch the electronic properties of the catalyst.

- Ion binding/ligand exchange: The reversibility of coordination bonds was used to control a catalyst's activity. For example, an added i) poisoning ligand can bind the catalytic metal thereby turning off the catalysis, which can be reversed by removing this particular ligand. Ligand exchange reactions were also used to engineer allosteric sites on catalysts: ii) addition of strong ligands in the media displaces weak ligands from 
allosteric metal, inducing a structural change affecting the catalytic site: iii) the structural constraint induced by the metal coordination of a polydentate ligand was used to pre-organize cooperative sites.

- Organic cofactor: An organic cofactor was shown to control the enantioselectivity of the reaction by interacting, noncovalently, with both catalyst and substrate.

- Enzymatic activity: Goggins et al. recently reported an enzyme-mediated upregulation of a catalyst in the context of signal amplification. ${ }^{[5]}$ They used a pre-catalyst that undergoes activity enhancement upon coordination by an amino-sulfonamide ligand. The primary amine of the ligand was masked by a self-immolative linker terminated by a phosphate group. Upon the action of a phosphatase, the ligand is unmasked, coordinates the metal of the pre-catalyst hence enhancing its transfer hydrogenation activity.

Enzymes are a source of inspiration for the development of catalysts because of their regulation properties but also because of their catalytic efficiency (e.g. regio- and enantioselectivity, soft conditions required). To mimic the latter, one strategy is to anchor an organometallic catalyst within a biological scaffold, resulting in an artificial metalloenzyme (ArM hereafter). The ArMs combine the attractive features of both enzymatic and (chemical) homogeneous catalysis. ${ }^{[6]}$ Several groups develop ArMs based on the biotin-streptavidin (Sav) technology, building on the seminal work of Whitesides. ${ }^{[7]}$ Our group demonstrated that the protein host of the ArM increases the bio-compatibility of its organometallic cofactor, enabling its use together with natural enzymes in cascade reactions. ${ }^{[8]}$ In addition, we have recently reported an
ArM performing catalysis in vivo. ${ }^{[9]}$ To pursue in this direction, i.e. further integration of a synthetic catalyst within the complex chemical network of a cell, one would like to render the synthetic catalyst controllable by cellular signaling, resembling the properties of an endogenous enzyme. To that end, the biological scaffolds of the ArMs offer great opportunities for chemists. Indeed, these scaffold are made of a biopolymer (protein or nucleic acid) for which a cell already possesses regulation means. Chemists may seize this opportunity to design biocompatible regulation systems for their ArMs. For example, the activity of an ArM could be unleashed by proteolysis of its protein scaffold by a natural protease, reminiscent of the natural zymogens (vide supra). We recently described the development of an artificial zymogen based on the biotin-streptavidin technology (Fig. 1). ${ }^{[10]}$

Similar to the system of Goggins et $a l .,{ }^{[5]}$ this upregulation system was based on a biotinylated $\mathrm{Cp} * \mathrm{Ir}$ moiety since it was already proven that i) $\left[\mathrm{Cp}^{* \text { biot }} \mathrm{IrCl}_{2}\right]_{2}$ (free or anchored within the wild type streptavidin (WT Sav)) has limited catalytic activity for imine reduction and ii) its complexation by a suitable ligand significantly increases its transfer hydrogenation activity. ${ }^{[5,11]}$ In addition, iii) embedding a Cp*Ir moiety within Sav prevents its inhibition by other enzymes, enabling its integration into an enzyme cascade. ${ }^{[8]}$

In the context of ligand-accelerated catalysis, ${ }^{[12]}$ the group of Hilvert screened a library of tripeptides to identify ligands that improve the $\left[\mathrm{Cp}^{*} \operatorname{Ir} \mathrm{X}_{3}\right]$-catalyzed transfer hydrogenation $\left(\mathrm{X}=\mathrm{Cl}^{-}\right.$or $\left.\mathrm{H}_{2} \mathrm{O}\right) .{ }^{[11 c]}$ The tripeptide glycine-glycinephenylalanine (GGF hereafter) yielded the most active complex. It is assumed to coordinate the iridium via the nitrogen atoms of the first two residues (i.e. a primary amine and an amide). ${ }^{[11 \mathrm{~b}, \mathrm{c}]}$ We took advan- tage of this property to build an artificial zymogen: we speculated that installing the tripeptide $\left(\mathrm{AA}^{1} \mathrm{AA}^{2} \mathrm{AA}^{3}\right.$ hereafter) at the $C$-terminus of the Sav would prevent its coordination to the iridium of the complex embedded in the biotin-binding pocket of Sav $\left(\left[\mathrm{Cp}^{* \text { biot }} \mathrm{IrX} \mathrm{X}_{3}\right] \subset \mathrm{Sav}\right)$. The action of a protease would then be required to liberate the tripeptide, which eventually could bind to the iridium of $\left[\mathrm{Cp}^{* \text { biot }} \mathrm{Ir} \mathrm{X}_{3}\right] \subset \mathrm{Sav}$ to yield the active complex. In other words, the protease would upregulate the artificial transfer hydrogenase (ATHase) activity of the zymogen (Fig. 1).

Both the tripeptide ligand and the Sav host were optimized independently in order to select a combination tripeptide/ Sav having both high ATHase activity and satisfying enantioselectivity. A library of XGF-type peptides was synthesized and tested, together with purified single and double mutants of Sav. ${ }^{[10]}$ In these experi-

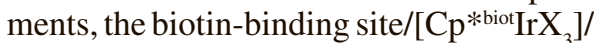
$\mathrm{AA}^{1} \mathrm{AA}^{2} \mathrm{AA}^{3}$ ratio was set to $2: 1: 2.2$ in order to drive the equilibria towards formation of the ArM ([Cp*biot $\operatorname{Ir}\left(\mathrm{AA}^{1} \mathrm{AA}^{2} \mathrm{AA}^{3}\right)$ $\mathrm{X}] \subset \mathrm{Sav}){ }^{[13]}$ The procedure followed was: i) mix $\left[\mathrm{Cp}^{* \text { biot }} \mathrm{IrCl}_{2}\right]_{2}$ and $\mathrm{Sav}$ in MOPS buffer (MOPS $=3-(N$-morpholino $)$ propanesulfonic acid) and incubate for $0.5 \mathrm{~h}$ at $37^{\circ} \mathrm{C}$; ii) add the synthetic tripeptide $\mathrm{AA}^{1} \mathrm{AA}^{2} \mathrm{AA}^{3}$ and incubate for $12 \mathrm{~h}$; iii) add sodium formate and substrate and stir the reaction for $24 \mathrm{~h}$ at $37^{\circ} \mathrm{C}$, then iv) analyze the reaction mixture by HPLC. Significant results are summarized in Table 1 (Entries 1-6).

These results confirmed that i) the cofactor has limited ATHase activity, and ii) the addition of tripeptide enhances it (Table 1, Entries 1-6), consistent with previous reports. ${ }^{[11 b-d]}$ The tripeptide SGF yielded the highest ATHase activity. In the case of substrate $\mathbf{2}$, the ATHase activity

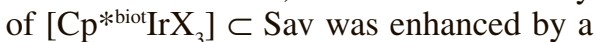

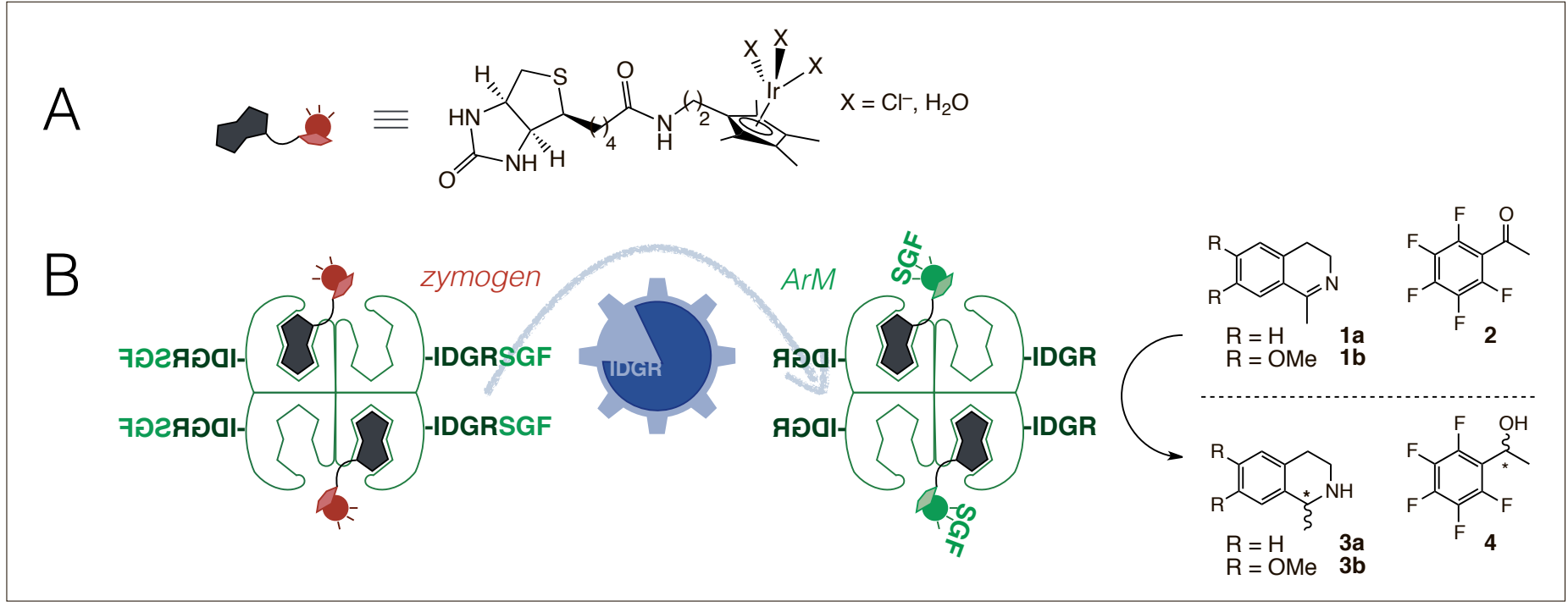

Fig. 1. The development of an artificial zymogen based on the biotin-streptavidin technology. 
Table 1. Reduction of substrates $\mathbf{1 a}, \mathbf{1} \mathbf{b}$ and $\mathbf{2}$ catalyzed by $\left[C p^{\star b i o t} \mid r\left(A A^{1} A A^{2} A A^{3}\right) L\right] \subset$ Sav, and Factor Xa activation of the artificial zymogen ${ }^{a}$

\begin{tabular}{|c|c|c|c|c|c|c|c|c|c|c|c|c|}
\hline \multirow{3}{*}{$\begin{array}{l}\text { Entry } \\
\qquad 1\end{array}$} & \multirow{3}{*}{$\begin{array}{l}\text { Sav mutant } \\
\text { K121A }\end{array}$} & \multirow{3}{*}{$\begin{array}{c}\text { Ligand } \\
-\end{array}$} & \multirow{3}{*}{$\begin{array}{c}\text { Factor Xa } \\
-\end{array}$} & \multicolumn{3}{|c|}{$1 a$} & \multicolumn{3}{|c|}{$1 b$} & \multicolumn{3}{|c|}{2} \\
\hline & & & & TON & \multicolumn{2}{|c|}{ ee [\%] } & TON & \multicolumn{2}{|c|}{ ee [\%] } & TON & \multicolumn{2}{|c|}{ ee [\%] } \\
\hline & & & & 199 & 10 & (R) & 46 & - & & 29 & - & \\
\hline 2 & $\mathrm{~K} 121 \mathrm{~A}$ & GGF & - & 1151 & 10 & (R) & 444 & 41 & (R) & 734 & 33 & (R) \\
\hline 3 & K121A & SGF & - & 1773 & 17 & (R) & 829 & 2 & (R) & 1431 & 38 & (R) \\
\hline 4 & K121A & YGF & - & 1161 & 25 & (R) & 444 & 46 & (R) & 1014 & 31 & (R) \\
\hline 5 & WT & SGF & - & 551 & 11 & (S) & 123 & 4 & (R) & 484 & 17 & (R) \\
\hline 6 & $\mathrm{~K} 121 \mathrm{E}$ & YGF & - & 888 & 21 & (R) & 457 & 73 & (R) & 290 & 7 & (R) \\
\hline 7 & K121A--SGF & - & - & 195 & 9 & (R) & 70 & 23 & $(R)$ & 23 & - & \\
\hline 8 & K121E--YGF & - & - & 130 & 1 & (R) & 36 & - & & 13 & - & \\
\hline 9 & K121A & - & + & 203 & 9 & (R) & 72 & 19 & (R) & 32 & - & \\
\hline 10 & K121E & - & + & 149 & 6 & (R) & 34 & - & & 13 & - & \\
\hline 11 & K121A--SGF & - & + & 2000 & 17 & (R) & 855 & 1 & (R) & 1778 & 39 & (R) \\
\hline 12 & K121E--YGF & - & + & 815 & 20 & (R) & 331 & 72 & (R) & 220 & 8 & (R) \\
\hline
\end{tabular}

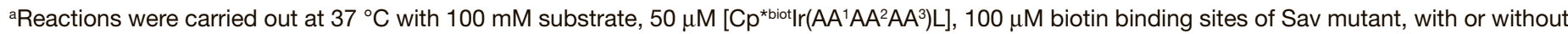
$5 \mu \mathrm{g}$ Factor Xa, $1.5 \mathrm{M}$ sodium formate in $0.6 \mathrm{M} \mathrm{MOPS}$ buffer $\mathrm{pH} 7.8$. All listed experiments were performed in triplicate: TON $\pm 10 \%$, ee $\pm 1 \%$; ee values are omitted for results with $\mathrm{TON}<50$ ).

factor 49 upon addition of SGF (Table 1, Entries 1 and 3). In addition, once the ArM was formed, its activity was robust: more than 3500 turnovers were obtained within $48 \mathrm{~h}$, using $300 \mathrm{mM}$ of substrate $2 .{ }^{[10]}$ The combination of the tripeptide YGF together with the Sav mutant K121E afforded an ArM that was less active, but showed a satisfying enantioselectivity (up to $73 \%$ ee $(R)$-3b) (Table 1, Entry 6).

Based on these results, the combinations tripeptide/Sav (SGF+K121A) and (YGF+K121E) were selected for the constructions of the artificial zymogens, i.e. the genetic encoding of the tripeptide at the $C$-terminus of Sav variants, spaced by a protease cleavage sequence. The serine protease Factor Xa, cleaving after the sequence IDGR, was selected. ${ }^{[14]}$ The protease recognition site, followed by the tripeptide, were encoded at the $C$-ter of the mature Sav, yielding the mutants abbreviated K121A--SGF and K121E--YGF. The ability of Factor Xa to release SGF or YGF when incubated with those Sav mutants was confirmed by UPLC-MS analysis. [10]

The artificial zymogens were constructed by embedding $\left[\mathrm{Cp}^{* \text { biot }} \mathrm{Ir} \mathrm{X}_{3}\right]$ within K121A--SGF and K121E--YGF. The ability of Factor Xa to upregulate their ATHase activity was assessed by adding Factor $\mathrm{Xa}$ just after mixing $\left[\mathrm{Cp}^{* \text { biot }} \mathrm{IrCl}_{2}\right]_{2}$ and $\mathrm{K} 121 \mathrm{X}_{1}-\mathrm{X}_{2} \mathrm{GF}$ in the protocol described earlier. Zymogen and protease were incubated $12 \mathrm{~h}$ prior to the addition of the formate and substrate. The results presented in Table 1 (Entries 7-12) confirmed the zymogen-behavior of this system: both the Factor $\mathrm{Xa}$ and the IDGRX $\mathrm{GF}_{2}$ sequence at the $C$-terminus of $S a v$ were required for a significant ATHase activity. In addition, the resulting activity (TON, ee) was simi- lar to that measured earlier, using synthetic peptides, confirming the identical nature of the ArM formed upon addition of Factor $\mathrm{Xa}$ to the artificial zymogen or upon addition of the synthetic peptide.

In conclusion, our group developed the first artificial zymogen, with latent ATHase activity, which is upregulated by a natural protease. This constitutes a first step towards the cellular activation of ArMs, which could be used in synthetic biology.

\section{Acknowledgment}

The author thanks Prof. Thomas R. Ward for his supervision and Novartis Pharma AG, the University of Basel and the National Swiss Foundation for generous support.

Received: January 27, 2017

[1] a) C. S. Mocny, V. L. Pecoraro, Acc. Chem. Res. 2015, 48, 2388; b) S. Ausländer, D. Ausländer, M. Fussenegger, Angew. Chem., Int. Ed. 2016, DOI: 10.1002/anie.201609229.

[2] J. M. Berg, J. L. Tymoczko, L. Stryer, G. J. Gatto, 'Biochemistry', 7 ed. Ed. W. H. Freeman, New York, 2011.

[3] a) C. Lazure, Curr. Pharm. Des. 2002, 8, 511; b) M. Ehrmann, T. Clausen, Annu. Rev. Genet. 2004, 38, 709 .

[4] a) V. Blanco, D. A. Leigh, V. Marcos, Chem. Soc. Rev. 2015, 44, 5341; b) V. Marcos, A. J. Stephens, J. Jaramillo-Garcia, A. L. Nussbaumer, S. L. Woltering, A. Valero, J. F. Lemonnier, I. J. Vitorica-Yrezabal, D. A. Leigh, Science 2016, 352, 1555; c) M. Vlatkovic, B. S. L. Collins, B. L. Feringa, Chem. - Eur. J. 2016 22, 17080; d) A. M. Lifschitz, M. S. Rosen, C. M. McGuirk, C. A. Mirkin, J. Am. Chem. Soc. 2015, 137, 7252; e) P. Dydio, J. N. H. Reek, Chem. Sci. 2014, 5, 2135.

[5] S. Goggins, B. J. Marsh, A. T. Lubben, C. G. Frost, Chem. Sci. 2015, 6, 4978 .

[6] a) F. Rosati, G. Roelfes, Chem CatChem 2010, 2, 916; b) J. C. Lewis, ACS Catal. 2013, 3 ,
2954; c) F. T. Yu, V. M. Cangelosi, M. L. Zastrow, M. Tegoni, J. S. Plegaria, A. G. Tebo, C. S. Mocny, L. Ruckthong, H. Qayyum, V. L. Pecoraro, Chem. Rev. 2014, 114, 3495; d) O. Pamies, M. Dieguez, J. E. Backvall, Adv. Synth. Catal. 2015, 357, 1567; e) T. Heinisch, T. R. Ward, Eur. J. Inorg. Chem. 2015, 3406; f) M. Hoarau, C. Hureau, E. Gras, P. Faller, Coord. Chem. Rev. 2016, 308, 445 .

[7] a) M. E. Wilson, G. M. Whitesides, J. Am. Chem. Soc. 1978, 100, 306; b) C. C. Lin, C. W. Lin, A. S. C. Chan, Tetrahedron: Asym. 1999 , 10, 1887; c) M. T. Reetz, J. J. P. Peyralans, A. Maichele, Y. Fu, M. Maywald, Chem. Commun. 2006, 4318; d) T. K. Hyster, L. Knorr, T. R. Ward, T. Rovis, Science 2012, 338, 500; e) M. Pellizzoni, G. Facchetti, R. Gandolfi, M. Fuse, A. Contini, I. Rimoldi, ChemCatChem 2016, 8 , 1665; f) V. Breker, H. Sak, G. Baracchi-Krause, N. Krause, Tetrahedron Lett. 2015, 56, 6513.

[8] a) V. Kohler, Y. M. Wilson, M. Durrenberger, D. Ghislieri, E. Churakova, T. Quinto, L. Knorr, D. Haussinger, F. Hollmann, N. J. Turner, T. R. Ward, Nat. Chem. 2013, 5, 93; b) Y. Okamoto, V. Kohler, C. E. Paul, F. Hollmann, T. R. Ward, ACS Catal. 2016, 6, 3553; c) Y. Okamoto, V. Kohler, T. R. Ward, J. Am. Chem. Soc. 2016, 138, 5781

[9] M. Jeschek, R. Reuter, T. Heinisch, C. Trindler, J. Klehr, S. Panke, T. R. Ward, Nature 2016 , $537,661$.

[10] Z. Liu, V. Lebrun, T. Kitanosono, H. Mallin, V. Kohler, D. Haussinger, D. Hilvert, S. Kobayashi, T. R. Ward, Angew. Chem., Int. Ed. 2016, 55,11587

[11] a) E. Steckhan, S. Herrmann, R. Ruppert, E. Dietz, M. Frede, E. Spika, Organometallics 1991, 10, 1568; b) W. Hoffmuller, H. Dialer, W. Beck, Z. Naturforsch. Sec. B 2005, 60, 1278; c) C. Mayer, D. Hilvert, Eur. J. Org. Chem. 2013, 3427; d) T. Quinto, F. Schwizer, J. M. Zimbron, A. Morina, V. Kohler, T. R. Ward, ChemCatChem 2014, 6, 1010 .

[12] D. J. Berrisford, C. Bolm, K. B. Sharpless, Angew. Chem., Int. Ed. 1995, 34, 1059.

[13] V. M. Robles, M. Durrenberger, T. Heinisch, A Lledos, T. Schirmer, T. R. Ward, J. D. Marechal, J. Am. Chem. Soc. 2014, 136, 15676.

[14] K. Nagai, H. C. Thogersen, Nature 1984, 309, 810 